\title{
The Automatic Consulting System in Higher Education Institution
}

\author{
Jarumon Nookhong and Nutthapat Kaewrattanapat
}

\begin{abstract}
This research was a research and development project that aimed to develop an automatic system to assist and support consultation about University information. These can be categorized into four groups: 1). Education; 2). Expenses; 3). Privacy issues and 4). other issues, and to assess the efficiency of the automatic consulting system. The system was developed in the form of mobile web access applications based on mobile queries, whereas THSplitlib was used for Thai word wrapping which was operated using Dictionary-Based Approach which compared input with the words stored in the dictionary. A review of the results of the assessment by experts found that the average total was at 4.25 with a standard deviation of 0.71 . This showed that the system's performance was good and that the assessment on the part of the experts tended in the same direction. It was concluded from the research that the counseling is effective in terms of improving automation levels.
\end{abstract}

Index Terms-Automatic consulting system, Thai-text classification, recommended system.

\section{INTRODUCTION}

At the present time, computer technology has become a functional part of the system. As It can be seen that computers have been applied in many different fields such as medicine, the military, transportation, communications, banking, commerce, business and education. Therefore, it can be said that this is the age of computers since the computer is involved in many of the things around us until it has become the thing to solve problems in education at all levels. As a result, educational institutions must adapt to meet the rapidly changing technology. The computer is therefore a part of technology that is important and which plays an important role in the development of technology in education [1]

The role of information and communications technology in the world today has evolved to the point where there are complex and divers until it becomes a critical tool of the modern world. Thailand is introducing improvements in information and communications technology to take advantage of the extensive and varied, both in terms of the management and the provision of government services, the reduction of costs and increases in efficiency in the industrial sector; the use of the learning processes for the benefit of education, as well as for civil society to improve the quality of life [1].

Most of the students at bachelor degree level are in their late adolescence or early adulthood, aged between 16 and 21

Manuscript received June 12, 2016; revised December 5, 2016.

The authors are with Faculty of Humanities and Social Sciences, Suan Sunandha Rajabhat University, Bangkok (SSRU), Thailand (e-mail: jarumon.no@ssru.ac.th,nutthapat.ke@ssru.ac.th). years of age who are full of eager curiosity but who have only limited experience of life. Upon entering higher education institutions, they therefore often have various personal, social and learning problems which are critically different from those involved in learning at the secondary level. The generally found problems are mainly related to inquiries and complaints about the university, learning and university information which cannot be answered by any department or division in line with demand. In order to make consulting easier and more convenient, there must be the central support system as a channel for allowing students to consult teachers more easily using a system which takes into account the convenience of both sides [2]-[5].

As a consequence, the researcher had the idea of developing an automatic consulting system in higher education institutions to support the teaching and to facilitate both learners and teachers in terms of contacting and consulting sources about various issues about the university. This automatic consulting system will record data Q\&A between the student and the teacher at all times in a database until a solution has been found that is complete and accurate as possible. After that, the system instead of the teacher will automatically answer when students ask the same question with the same characteristics or in the same manner. The aim is to widen the channel of consultation between students and professors in order to conveniently and quickly achieve communication between the university and its students to help such students in all aspects of development, to promote their lives on campus, and to solve them properly until graduation in such a way as to make graduates more effective.

\section{RESEARCH OBJECTIVES}

1) To develop the Automatic-Consulting System.

2) To assess the Automatic-Consulting System.

\section{ReSEARCh METHODOLOGY}

The Research and development format can be divided into 2 phases as follows:

\section{A. The Development of an Automatic-Consulting System Comprised the Following Steps}

1) The development of an automatic consulting system was done through the analysis and synthesis of related documents and research in order to define and guide the design of the automatic consulting system for supporting the learning and consulting between students and teachers. The problems were categorized into 4 groups 
as follows: 1). learning; 2). expense; 3). private issues and; 4). other issues.

2) System Analysis and Design: In the event that the students have a question or problem related to university information, students can access the developed system to request information or complain about their problems. The system then analyzes, inspects the students' questions, and reports the question to the teachers. After the teachers have finished answering the questions, the system then reports the answers to the students and continuously records the history of Q\&A. After that, the system will choose the best answer for each question in such a way that it answers the students automatically. Each time the students ask the same questions, the system will perform as shown in the chart (Fig. 1.) which illustrates the performance of system in the form of a Detail of system architecture.

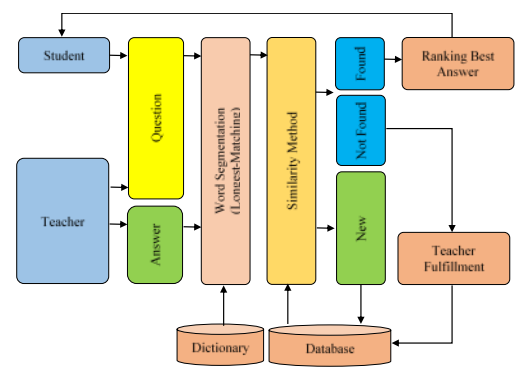

Fig. 1. System architecture.

Fig. 1 shows the system architecture: a diagram showing the scope of work of the details of the cases used by the system.

3) The Automatic Consulting System uses PHP and HTML as the language for writing the system and uses an SQL database (MySQL) to store data. This is because the database comes with a SQL (MySQL) as a relational database. The data is supplied in the form of tables, easy to run, add, delete, edit the information to be written-on applications brand jacket (Brackets) system to develop into a mobile web application with functionality (Mobile Web. application) by using the mobile query (JQUERY MOBILE). This will help to design a web interface that is consistent with the experience of mobile devices available for use at present.

\section{B. The Assessment of the Automatic Consulting System Comprised Following Steps}

1) The developed system was presented to 10 experts in consulting and information technology to allow them to analyze and assess the system in 4 aspects: 1 . Function Requirement Test 2. Function Test 3. Usability Test 4. Security Test.

2) Analyzing the assessment result of the system based on the average criteria $(\bar{X})$ and standard variation (S.D.) through the assessment form at the basis of the weight as a standard part of a 5 level rating scale by means (Likert).

\section{RESEARCH RESULT}

This research presented the results in 2 phases as follows:

\section{A. The Results of the System Development Was Detailed as Follows}

1) A sample of word wrapping performance: the word wrapping in Dictionary

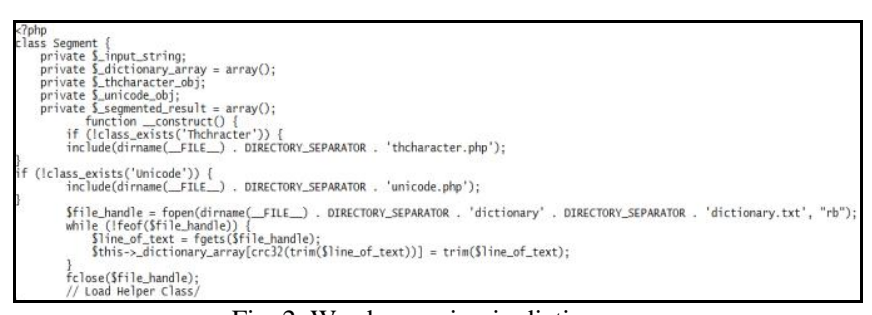

Fig. 2. Word wrapping in dictionary.

2) Sample of word wrapping performance: Wrapped word using

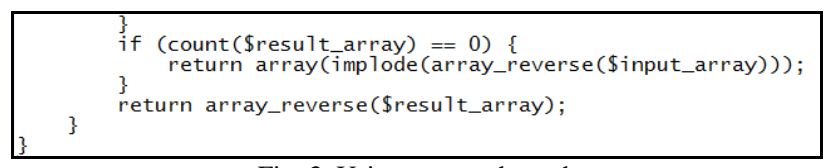

Fig. 3. Using wrapped word.

3) Sample of word wrapping performance: The record of wrapping used in the database

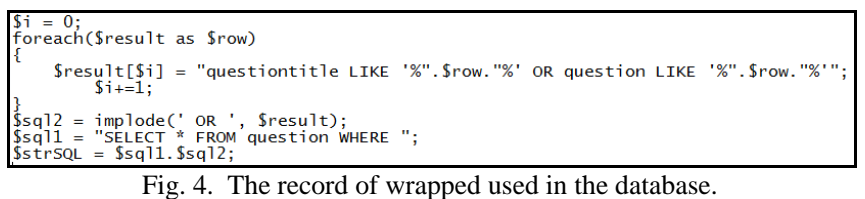

4) Main page of the general users as shown in Fig. 5.

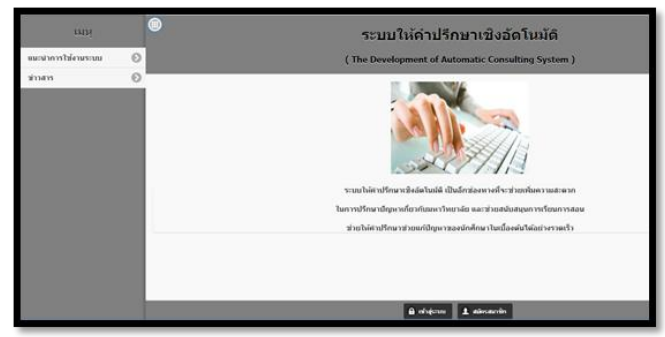

Fig. 5. The first page of the system.

5) Student Page: The main page shall display the detected and consulted problem for students who access the system. This allowed the students to find answers to their problem. If there is any consulted problem, the students can apply the approach recommended in Fig. 6.

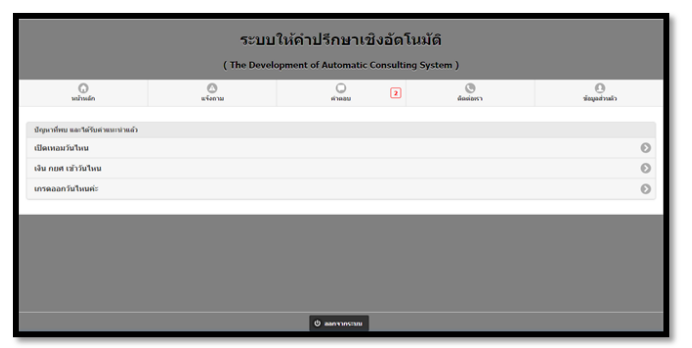

Fig. 6. The main page of the system.

6) Student Page: Inquiry Part- when the student inputs the data, the system will display the question and the closest answer. If the student cannot find the answer to the question and press the send button, the system will send the question to the teacher as shown in Fig. 7. 


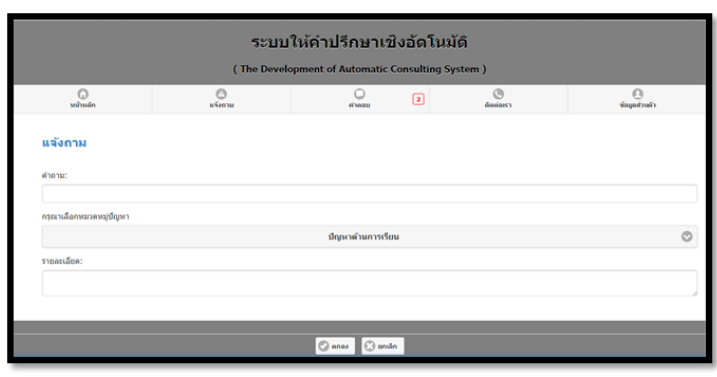

Fig. 7. Illustration of the inquiry.

7) Student Page: The answer screen displays all questions asked by students, both with and without the answers as shown in Fig. 8.

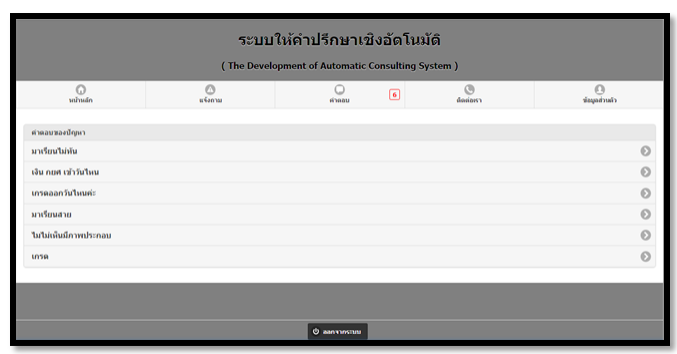

Fig. 8. Illustration of the answer page.

\section{B. The Result of the System Assessment Was Concluded as} Follows

1) The results of the developed system assessment involving 10 experts in 4 aspects was as follows: 1). Function Requirement Test; 2). Function Test; 3). Usability Test and 4). Security Test as shown in Table I:

TABLE I: THE SYSTEM ASSESSMENT RESULTS BY EXPERTS

\begin{tabular}{lccl}
\hline \hline tsiL tnemsessA & $\bar{X}$ & S.D. & Result \\
\hline 1. Function Requirement Test & 4.40 & 0.49 & Good \\
\hline 2. Function Test & 4.20 & 0.75 & tnellecxE \\
\hline 3. Usability Test & 4.20 & 0.75 & Good \\
\hline 4. Security Test & 4.20 & 0.87 & Good \\
\hline Assessment Results & 4.25 & 0.71 & Good \\
\hline \hline
\end{tabular}

From Table I, it can be seen that the system assessment results by experts showed that the overall system was operating at a good level. The system focused on consulting problems related to university information in order to widen the consulting channel between teachers and students to make it more convenient and faster by displaying the information in the form of Q\&A with the step-by-step solution that facilitates the accessing of data [6], [7]. This consulting system can solve problems and service the consultants at a good level.

\section{CONCLUSION}

The automatic consulting system for assisting and supporting learning and allowing consulting between students and teachers can be categorized into four groups: 1 ). Education; 2). expenses; 3). privacy issues and 4. other issues. The development of an automatic consulting system can solve problems and can respond to the use and support of learning on the network. The system focuses on consulting the issues related to university information [8]-[10]. The system was introduced to widen the channel of consultation between students and teachers to make it faster and more convenient. This is because teachers are the people who have a close relationship with students and representatives of the university in order to support students in terms of academic, personal and social problems to enhance the process of communication between university and students, including making students feel comfortable, relying on all aspects that lead to the development and promotion of students when it comes to living on campus and solving problems properly until graduation to make graduates more effective [11].

\section{ACKNOWLEDGMENT}

We would like to thank the Institute for Research and Development's Suan Sunandha Rajabhat University's fund for supporting this research study and for providing sponsorship.

\section{REFERENCES}

[1] Ministry of Information and Communication, "ICT and communication policy framework," For 2011-2020.

[2] N. Rattanparanon, "The development of multi channel consulting service for the students via learning website, self-learning language center," Master of Science in Industrial Education, Department of Computer Technology Graduate Studies, King Mongkut's University of Technology, North Bangkok, Bangkok, 2011.

[3] P. Homhun, "The development of consulting and answering system in the library service: A case studies of Rajamangala University of Technology Rattanakosin Salaya," Master of Science in Industrial Education, Department of Computer Technology Graduate Studies, King Mongkut's University of Technology North Bangkok, Bangkok, 2011.

[4] N. Kaewrattanapat and J. Nookhong, “A comparison of performance prediction in the computer professional groups between multiple discriminant analysis and multinomial logistic regression analysis," in Proc. Seventh TheIIER International Conference, Singapore, $3^{\text {rd }}$ January 2015.

[5] P. Uradhamakul, "Thai word Wrapping by Improving the rules and a new dictionary," Computer Engineering Department, Khonkaen University.

[6] W. T. N. Ayutthaya, "Development of counseling students for higher education institutions in Bangkok," Bachelor of Philosophy, Chulalongkorn University, Bangkok, 2011.

[7] W. Tuinoi, "The development of advisors online: A case study of Faculty of Information Technology," Master of Science, Department of Computer Science, University of Nations, 2013.

[8] S. N. Songkla, "The development of consulting system on internet for Burapha University," Master of Science in Industrial Education. Department of Computer Technology Graduate Studies, King Mongkut's University of Technology North Bangkok, Bangkok, 2011.

[9] S. Techorote, "The development of consulting system for quality assurance studies," Rajamangala University of Technology Phra Nakhon. Bachelor Science, Department of Computer Science, Rajamangala University of Technology Phra Nakhon, Bangkok, 2014.

[10] O. Klubsakul, "The development of consulting system for supporting the learning via website," Master of Science in Industrial Education. Department of Computer Technology Graduate Studies, King Mongkut's University of Technology North Bangkok, Bangkok, 2010.

[11] A Handbook of Academic Consulting System fo Bachelor Degree. [Online]. Available: Government Institutions of Higher Education.http://apr.nsru.ac.th/Course_web/TQF/File/advisor\%20\%E 0\%B8\%AA\%E0\%B8\%81\%E0\%B8\%AD..pdf

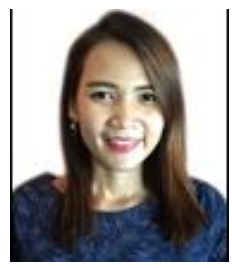

Jarumon Nookhong is lecturer of information science, Faculty of Humanities and Social Sciences at Suan Sunandha Rajabhat University, Bangkok (SSRU), Thailand. She got her bachelor degree of information science (information management) Walailak University. Also, she graduated her master of sciences (management information system) King Mongkut's University of Technology North Bangkok and $\mathrm{Ph} . \mathrm{D}$. candidate in information and communication technology for education from King Mongkut's University of Technology North Bangkok, Thailand. She's research focuses on data mining, knowledge management, 
artificial neural networks, green ICT, cloud computing and green cloud system.

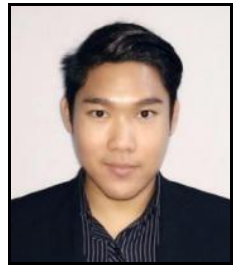

Nutthapat Kaewrattanapat is currently a faculty member of information science, Faculty of Humanities and Social Sciences at Suan Sunandha Rajabhat University, Bangkok (SSRU), Thailand since 2009. He was born on March 8, 1983 in Thailand and received his B.S. degree with 1st class honors in computer science and the M.S. degree in management information system and the Ph.D. candidate in information technology (Royal Thai Government scholarship) from King Mongkut's University of Technology North Bangkok, Thailand. His research focuses on information technology, computational linguistic, natural language processing: NLP and data mining. 